DOI: 10.21767/2171-6625.S10012

\title{
Spinal Cord Herniation: Why Anterior Thoracic?
}

\section{Abstract}

Background: Spinal cord herniation and thoracic anterior adhesion syndrome make up the two extremes of a rare condition; characterized by anterior dural adhesion or protrusion of the spinal cord through the arachnoideal and dural membrane into the extradural space, respectively.

Summary: We present the main features of the condition by our case series and forward a hypothesis for the consistent anterior, mid-thoracic localization. We surmise the role of an anterior pulling force by the Hofmann (meningo-vertebral) ligaments; acting when the physiologic thoracic kyphosis suddenly increases. The traction may tear the anterior dura; resulting in a dural defect; it allows the nipping/ protrusion of the spinal cord.

Key messages: Because the spinal cord compression syndrome caused by adhesion or herniation of the spinal cord may be surgically treatable; the recognition of the condition is essential. The pathogenetic traction effect of the Hofmann ligament in the affected level may have surgical an prognostic implications.

Key words: Spinal cord herniation; Meningo-vertebral ligament; Dural sac; Spinal cord compression

Received: November 08, 2015; Accepted: September 02, 2015; Published: September 04, 2015

\section{Introduction}

The term spinal cord herniation ( $\mathrm{SCH}$ ) describes the displacement of the spinal cord out of the dural sac through a defect of the arachnoidal membrane and the dura mater [1,2]. In mild cases there is just an anterior ventral adhesion of the spinal cord to the dura mater, which can be visualized on magnetic resonance imaging (MRI). This condition is termed thoracic anterior spinal cord adhesion syndrome (TASCA) [3]. In advanced cases significant protrusion or bulge of the spinal cord, reaching centimeters' size may develop through the ventral split of the dura. Involvement of more than one spinal region is rare [4].

About 100 cases of $\mathrm{SCH}$ have been reported in the literature. Due to the improvement of imaging methods, the number of recognized cases has been increasing. Apparently, most reported cases were associated to traumas [5], following them sometimes decades later [6]. There are "spontaneous" or "idiopathic" [2,7-10]; and rarely, iatrogenic cases reported. Extremely rare are those cases where the spinal cord herniates into pseudomeningokeles caused by traumatic nerve root avulsion [11,12].

\author{
Anna Szúcs*, \\ András Horváth, \\ Péter Várallyay, \\ Eszter Turányi, Éva Osztie, \\ Géza Szabó, \\ Attila Bagó, \\ Anita Kamondi and \\ Péter Banczerowski
}

National Institute of Clinical Neurosciences, Amerikai rd 57, 1144 Budapest, Hungary

\section{Corresponding author: Dr. Anna Szücs}

\section{Szucsan@gmail.com}

National Institute of Clinical Neurosciences, 57 Amerikai rd. 1144 Budapest, Hungary.

Tel: 0036306894262

Citation: Szűcs A, Horváth A, Várallyay $P$, et al. Spinal Cord Herniation: Why Anterior Thoracic?. J Neurol Neurosci. 2015, S1. the spine; are also rare [13].

The main MRI features of SCH are the followings [14,15]:

- Regional spinal cord attenuation; pulled to the anterior wall of the spinal canal.

- There is a dilated cerebrospinal fluid (CSF) space behind the attenuated spinal cord. This posterior dilation of the CSFspace may resemble to an arachnoid cyst; then it is found to be a secondary dilation made by the displacement of the spinal cord. (A primary retro-medullar arachnoid cyst may be excluded by contrast-enhanced CT-myelography as well as by the CSF pulsation artefacts on the MRI).

- The ventral CSF space is obliterated by the dislocated spinal cord.

- Careful observation may help identifying the spinal bulge in the epidural space, ventrally from the dura mater.

The spinal distortion may result in progressive spastic paraparesis or Brown-Séquard syndrome $[16,17]$. Careful surgical reposition 
of the spine and reconstruction of the dura through a posterior opening may help in selected cases $[18,19]$.

We present three cases of SCH seen in the National Institute of Clinical Neurosciences, Budapest, for calling attention to this rare condition and for contributing to the understanding of its mechanism and management. Because there are effective surgical methods for treating patients suffering in spinal cord compression syndromes related to this condition, it is essential for clinicians and neuro-radiologists to be aware of and recognize $\mathrm{SCH}$.

\section{Our Cases}

- We admitted to our neurology unit the slim and small statured 45-year-old lady for intense back pain and an acute paraparesis, evolving when she sprang down from the windowsill after cleaning the window. She developed urinary retention, pyramidal signs affecting both lower limbs and sensory changes suggesting a mid-thoracic lesion. The MRI of the thoracic spine revealed a step-like protrusion and anterior adhesion of the spinal cord to the dura mater, at level Th5-6 (Figure 1A-1C). A CSF pulsation artefact posterior to the cord was readily visualised and thus a posterior arachnoid cyst was excluded. She received steroid and pain-release treatment, her spinal cord syndrome has perfectly resolved within days. Six months later the adhesion and echelon-bulge of the spine was decreased on MRI, and a follow up MRI a year later has revealed an unchanged residual asymmetrical anterior thoracic bulge; she has had no neurology signs but some back pains (Figure 1D-1F).

- The 36-year-old man was seen because of severe back pain and tingling sensation of the thighs. He had no additional neurological signs. He has been symptoms-free in the mornings but intense pain has developed every afternoon after working for hours on his computer. He had had no trauma or injury. The MRI of the thoracic spine revealed an anterior spinal cord adhesion and protrusion at level Th 5/6 (Figure 2), with CSF pulsation artefact posterior to the cord, excluding an arachnoid cyst. His condition has not required an operation; he has been treated with nonsteroid pain-killers.

- The 44-year-old female had progressive leg weakness. Her past medical history was unremarkable, her sister died due to Wilson's disease. Her right foot-drop and occasional involuntary jerks in the knees and ankles started 9 years before. At admission she was generally fit with a spastic, grade $3 / 5$ paresis of the right lower limb. Her upper limb deep tendon reflexes (DTRs) were normal while the DTRs on the lower limbs were pathologically brisk (right>left), and the plantars went up on the right leg. There was a reduction in fine touch and pin prick sensation below level Th 7 on the right side. She had normal autonomic functions.

Her brain CT and MRI scans, electroencephalography, nerve conduction studies on peripheral nerves and Wilson genetics were normal. Her thoracic MRI spine scan has revealed the abnormal shape and spinal cord signal change at level Th 7-8 suggesting an assymmetrical spinal cord herniation or TASCA behind a small disc bulge at that level (Figure 3). In intratracheal narcosis a costo-transversectomy was performed. The dural sac was seen well from root to root. The dura was longitudinally opened between the two roots. There was a defect of the dura mater seen. Touching in, we noticed a big cavity made of a dural duplication below the herniation. The dura was not sticked to the spinal cord, and the spinal cord did not protrude into the cavity. We cut the orifice longitudinally then doing star-like cuts further, so the cavity became scoop-like, tubby; its orifice has disappeared. We closed the dura mater. Rehabilitation treatment resulted in full recovery of the patient.

\section{Discussion}

Our three cases represent the spectrum of $\mathrm{SCH}$ from back pain only (patient 2) to spinal cord compression syndrome (patient 3); and from TASCA (patient I and 2) to an important dural cavity able to let the spinal cord protrude in it (patient 3); as seen on Figure 3; needing surgery. The TASCA of patient 1 has improved spontaneously.

In our patients and in most published cases of the literature [2024] the mid-thoracic spine was involved and the spinal dislocation was ventral. Just one dorsal SCH-case has been reported [25].

The thoracic localization of $\mathrm{SCH}$ might simply be related to the length and weight carried by the thoracic spine. The fascinating
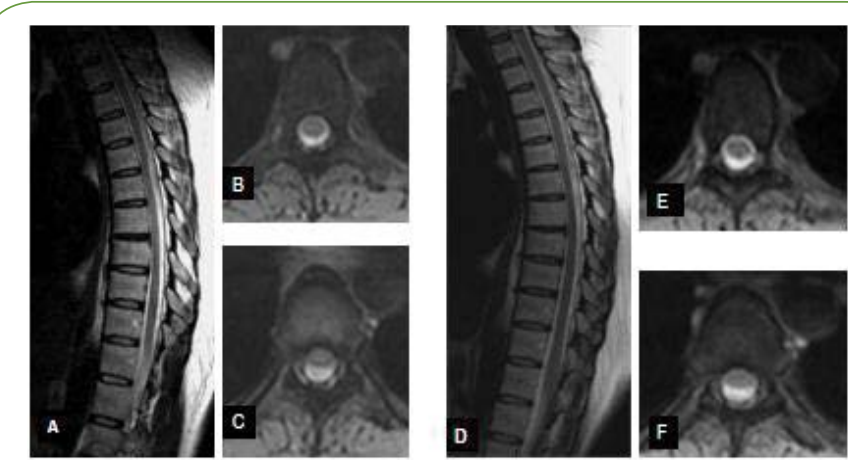

Figure 1 Sagittal and axial T2-weighted images at presentation $(A, B, C)$ and at follow-up 13 months later $(D, E, F)$. Sagittal T2-weighted image (A) shows focal anterior displacement of the spinal cordat T5/6. No pathological intramedullary sginal alterations are detected. Note the CSF pulsation artefact seen as faint, patchy signal changes in the widened CSF space posterior to the cord. Corresponding axial T2-weighted images at T5 (B) and at T5/6 disc space level (C) demonstrate effacement of the anterior subarachnoid space and anterior displacement of the cord with associated widening of the posterior subarachnoid space at T5/6 (C) compared to the normal position of the cord slighty above at T5 (B), where the anterior CSF space is also visualised. Follow-up study 13 months later discloses less anterior displacement and only a minimal residual anterior angulation of the cord (D). Also, the axial image at $\mathrm{T} 5 / 6$ shows reappearance of the anterior CSF space (F), almost similar to that seen slightly above at T5. 

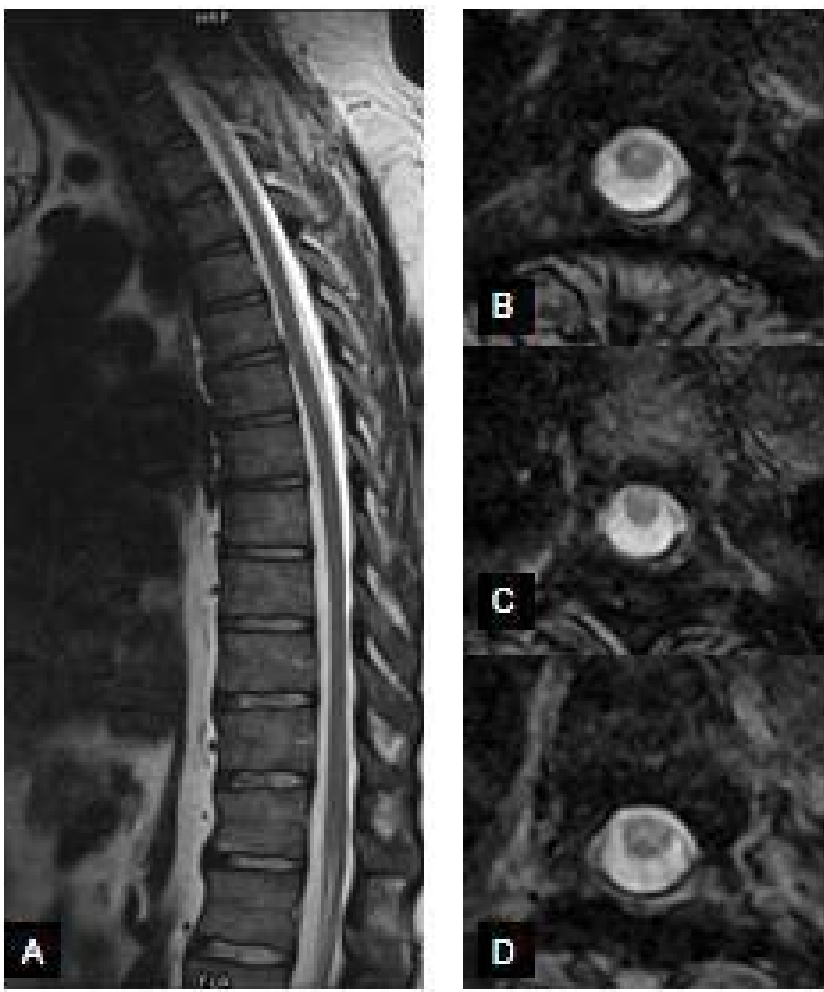

Figure 2 Sagittal (A) and axial T2-weighted images (B,C,D). Sagittal T2-weighted image (A) shows focal anterior displacement/adhesion of the spinal cord at T5/6. Faint linear CSF pulsation artefact is seen in the widened CSF space posterior to the cord. The cord returns a normal signal intensity. Corresponding axial T2-weighted images at T5 (B), at T5/6 disc space level (C) and at T6 (D) demonstrate effacement of the anterior subarachnoid space, anterior displacement and mild elongation of the AP diameter of the cord with associated widening of the posterior subarachnoid space at T5/6 (C) compared to the normal position of the cord slighty above at T5 (B) and below at T6 (D), where the anterior CSF space is normally detected.

ventral displacement of the spinal cord seems more intriguing. The cord's ventral localization within the dural sac is not surprising, considering the kyphosis of the spinal column containing the perpendicular spinal cord. Based on simple mechanical rules, the spinal cord approaches the anterior wall of the canal. It gets closest where the curvature is maximal; at level Th5/6.

The most accepted theory of $\mathrm{SCH}$-supported by intraoperative observations-is that there would be a defect (posttraumatic or congenital) on the anterior aspect of the dural and arachnoideal membranes, allowing the spinal cord to get nipped and/or protrude out of the dural sac [26-28]. Ewald et al., [29] have forwarded a proposition on the preexisting weakness of the ventral dural fibers combined with abnormal adhesion of the spinal cord to the anterior dural sleeve, leading progressively to herniation. However, this porposition fails to explain the preferred ventral vulnerabity of the dura; that, to our knowledge, has remained unexplained by any developmental or anatomical
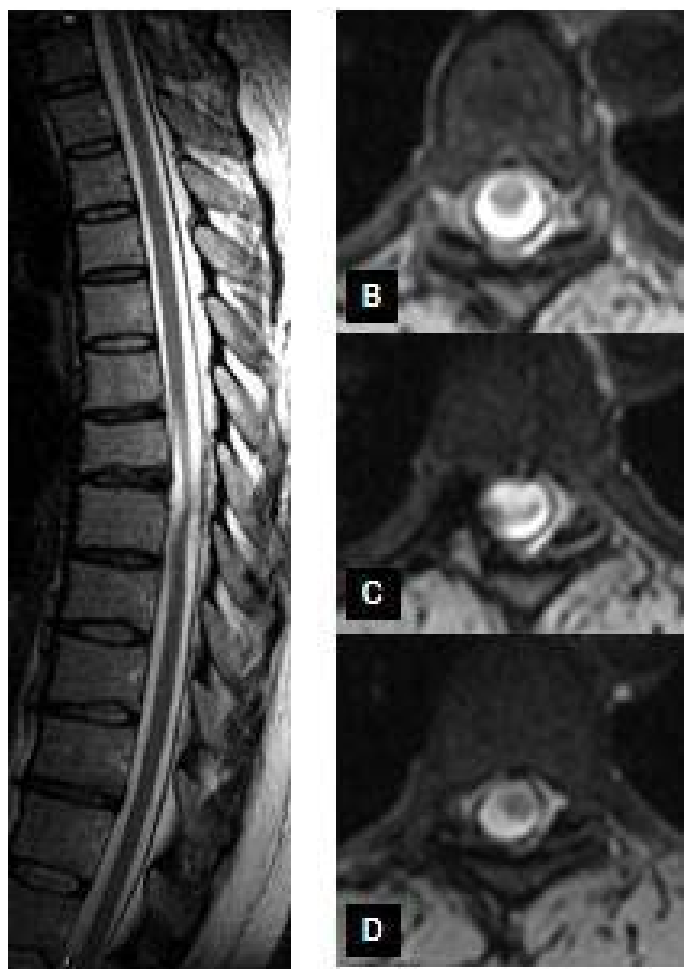

Figure 3 Sagittal (A) and axial T2-weighted images (B,C,D). Sagittal T2-weighted image (A) shows focal anterior adhesion of the spinal cord at T7-8 with an amorphous area of myelomalatia extending from the T6-7 disc space level to the mid T8. Corresponding axial T2weighted images at T6 (B), at T7-8 disc space level (C) and at the lower endplate of T8 (D) demonstrate obliteration of the anterior subarachnoid space and anterior adhesion of the cord with myelomalatia at T7-8 (C) compared to the normal position and signal intensity of the cord at T6 (B) and mild deformity of the cord with normal signal at the lower endplate of T8 (D).

factor.

We hypothesize that the arachnoideal/dural defects may evolve due to an anterior traction; a pulling force acting when the kyphotic curve of the spinal column suddenly increases- its becomes more bent-in reaction to a vertical force. When the sweep increases, the anterior pulling force jerks the dural sac ventrally. This hitch may result in the ventral tear of the arachnoideal and dural sac at that level. The Hofmann (meningo-vertebral) ligaments anchoring the dural sac to the posterior longitudinal ligament; may be able to exercise such a traction [30-32]. Figure 4 is our photo on a cadaver's opened thoracic spine, showing slightly skew Hofmann ligaments.

Wadhwani et al. have thoroughly examined these ligaments. Based on cadaver studies they say: "The orientation of the ligaments changes from caudo-cranial at upper thoracic levels to transverse at the level of Th8-Th9 to cranio-caudal at lower thoracic and lumbar levels, often with multiple ligaments being present at a single level. Ligament length varies from 0.5 to $28.8 \mathrm{~mm}$ and is positively correlated with vertebral level and negatively correlated with 


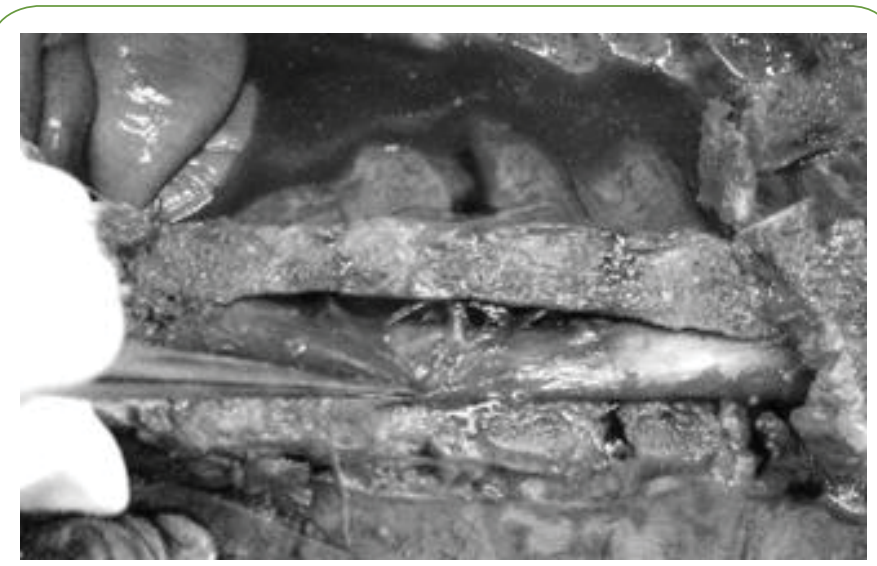

Figure 4 Photo on the opened spinal canal of a cadaver. The skew Hofmann ligaments anteriorly from the spinal cord are well seen (white arrows). In-between them there is a spinal nerve, perpendicular to the spinal cord. orientation. Hofmann ligaments are present at most levels between C7 and L5; although most ligaments are limited to a single vertebral segment, some were observed to cross several segments" [33]. It is likely that shorter and more horizontal ligaments dispose to the dural tear; in combination with an appropriate mechanical effect. More robust Hofmann ligaments in the lumbar region have been involved in the mechanism and high prevalence of lumbar disc bulges, with a similar, opposite-direction traction theory [34].

The evolving dural defect allows the spinal cord to protrude anytime. This may explain, why even decades might pass after a significant spinal trauma, until SCH-signs develop [6].

The anterior traction theory related to the Hofmann ligaments may have a preventive neurosurgical implication: finding and sharply cutting through the Hofmann ligament in the level of the dural slit may prevent re-tear and relapse to spinal herniation, as it has been occasionally seen after surgical solution [9].

\section{Funding}

Our research was supported by the National Brain Research Program (KTIA_NAP_13-1-2013-0001).

\section{Competing Interest}

Authors have no conflict of interest and nothing to disclose. 


\section{References}

1 Wortzman G, Tasker RR, Rewcastle NB, Richardson JC, Pearson FG (1974) Spontaneous incarcerated herniation of the spinal cord into a vertebral body: a unique cause of paraplegia. Case report J Neurosurg 41: 631-635.

2 Aizawa T, Sato T, Tanaka Y, Kotajima S, Sekiya M, et al. (2001) Idiopathic herniation of the thoracic spinal cord: report of three cases. Spine (Phila Pa 1976) 26: 488-491.

3 Taylor TR, Dineen R, White B, Jaspan T (2014) The thoracic anterior spinal cord adhesion syndrome. Br J Radiol 85: 123-129.

4 Aydin AL, Sasani M, Erhan B, Sasani H, Ozcan S, et al. (2011) Idiopathic spinal cord herniation at two separate zones of the thoracic spine: the first reported case and literature review. Spine J 11(8):9-14.

5 Francis D, Batchelor P, Gates P (2006) Posttraumatic spinal cord herniation. J Clin Neurosci 13: 582-586.

6 Urbach H, Kaden B, Pechstein U, Solymosi L (1996) Herniation of the spinal cord 38 years after childhood trauma. Neuroradiology 38: 157-158.

7 Castelnovo G, Hladky JP, Renard D (2014) Spontaneous transdural spinal cord herniation. Neurology 82: 1290.

8 Sioutos P, Arbit E, Tsairis P, Gargan R (1996) Spontaneous thoracic spinal cord herniation. A case report. Spine (Phila Pa 1976) 21: 1710-1713.

9 Selviaridis P, Balogiannis I, Foroglou N, Hatzisotiriou A, Patsalas I (2009) Spontaneous spinal cord herniation: recurrence after 10 years. Spine J 9: 17-19.

10 Tekkök IH (2000) Spontaneous spinal cord herniation: case report and review of the literature. Neurosurgery 46: 485-491.

11 Tanaka M, Ikuma H, Nakanishi K, Sugimoto Y, Misawa H, et al. (2008) Spinal cord herniation into pseudomeningocele after traumatic nerve root avulsion: case report and review of the literature. Eur Spine J 17 Suppl 2: S263-S266.

12 DaSilva VR, Al-Gahtany M, Midha R, Sarma D, Cooper P (2003) Upper thoracic spinal cord herniation after traumatic nerve root avulsion. Case report and review of the literature. J Neurosurg 99: 306-309.

13 Miyaguchi M, Nakamura H, Shakudo M, Inoue Y, Yamano Y (2001) Idiopathic spinal cord herniation associated with intervertebral disc extrusion: a case report and review of the literature, Spine (Phila Pa 1976) 26: 1090-1094.

14 Kenéz J, Barsi P, Várallyay $G$, Bobest $M$, Veres $R$ (2002) MR investigation of spinal cord herniation in the thoracic spine. Ideggyogy Sz 55: 168-172.

15 Kwong Y, Jakanani G, Rao N, Fang CS (2010) MRI findings in herniation of the spinal cord. Radiology Case 4: 1-5.

16 Borges LF, Zervas NT, Lehrich JR (1995) Idiopathic spinal cord herniation: a treatable cause of the Brown-Sequard syndrome-case report. Neurosurgery 36: 1028-1032.

17 Ewald C, Hassler WE (2001) Spontaneous herniation of the thoracic spinal cord as the etiology of progressive Brown-Sequard syndrome. A description of 3 cases. Nervenarzt 72: 441-444.

18 Ulivieri S, Olivieri G, Petrini C, D'Elia F, Cuneo GL (2008) Thoracic spinal cord herniation: case report and technical note. Neurol Neurochir Pol 43: 86-89.

19 Arts MP, Lycklama à Nijeholt G, Wurzer JAL (2006) Surgical treatment of idiopathic transdural spinal cord herniation: a new technique to untether the spinal cord. Acta Neurochir (Wien) 148: 1005-1009.
20 Sasani M, Ozer AF, Vural M, Sarioglu AC (2009) Idiopathic spinal cord herniation: case report and review of the literature. Spinal Cord Med 32: 86-94.

21 Darbar A, Krishnamurthy S, Holsapple JW, Hodge Jr CJ (2006) Ventral thoracic spinal cord herniation: frequently misdiagnosed entity. Spine 31: 600

22 Krishnan P, Kartikueyan R, Chowdhury D, Saha M (2013) Ventral herniation of the dorsal spinal cord: a rare cause of myelopathy. Neurol India 61: 453-454.

23 Miura Y, Mimatsu K, Matsuyama Y, Yoneda M, Iwata H (1996) Idiopathic spinal cord herniation. Neuroradiology 38: 155-156.

24 Gimena RB, Sánchez HJ, Sousa OJ, Larrañaga F (2004) Transdural herniation of the spinal cord: a rare cause of myelopathy. Rev Neurol 41: 757.

25 Alkan O, Kizilkilic O, Karakurum GB, Yildirim T, Sarica FB (2008) Ventral thoracic spinal cord herniation: a commonly misdiagnosed and treatable cause of myelopathy. Neuroradiol J 21: 563-567.

26 Ghostine S, Baron EM, Perri B, Jacobson P, Morsette D, et al. (2009) Thoracic cord herniation through a dural defect: description of a case and review of the literature. Surg Neurol 71: 362-366.

27 Le TC, Grunch BH, Karikari IO, Mehta Al, Owens TR, et al. (2012) Dorsal thoracic spinal cord herniation: report of an unusual case and review of the literature. Spine J 12: e9-12.

28 Inoue A, Kohno K, Takeda T, Okuda B, Takechi A, et al. (2006) A case of high-aged idiopathic spinal cord herniation from dural defect. No Shinkei Geka 34: 627-631.

29 Maruichi K, Hida K, Seki T, Iwasaki Y (2004) Idiopathic spinal cord herniation which extended remarkably up- and downward from dural defect: case report. No Shinkei Geka 32: 509-512.

30 Wiltse LL, Fonseca AS, Amster J, Dimartino P, Ravessoud FA (1993) Relationship of the dura, Hofmann's ligaments, Batson's plexus, and a fibrovascular membrane lying on the posterior surface of the vertebral bodies and attaching to the deep layer of the posterior longitudinal ligament. An anatomical, radiologic, and clinical study. Spine (Phila Pa 1976) 18:1030-1043.

31 Loughenbury PR, Wadhwani S, Soames RW (2006) The posterior longitudinal ligament and peridural (epidural) membrane. Clin Anat 19: 487-492.

32 Kimmell KT, Dayoub H, Shakir H, Sincoff EH (2011) Spinal dural attachments to the vertebral column: An anatomic report and review of the literature. Surg Neurol Int 2: 97.

33 Wadhwani S, Loughenbury P, Soames R (2004) The anterior dural (Hofmann) ligaments. Spine (Phila Pa 1976) 29: 623-627.

34 Bashline SD, Bilott JR, Ellis JP (1996) Meningovertebral ligaments and their putative significance in low back pain. J Manipulative Physiol Ther 19: 592-596.

An Original publication of ImedPub in a Special Issue-Current Trends in Neurodegenerative Diseases and Medical Procedures, Edited by Dr. Jianqi Cui, Department of Biochemistry and Molecular Biology, School of Basic Medical Sciences, Ningxia Medical University (NXMU), PR China. 